XI. Ueber die allotropischen Zustände des Schwefels; oon G. Magnus.

Vor Kurzem hat Hr. Mitscherlich gezeigt ") dafs die Verbindung von Schwefel mit einem Fette oder einem Oele, sich in Schwefel löst, und diesen aufserordentlich stark färbt, so dafs ein Theil Talg mit 3000 Theilen Schwefel erbitzt, eine intensiv rothe Masse liefert. Ich habe diese Versuche wiederholt und mich überzeugt, dafs nicht nur die Fette, sondern auch eine grofse Menge anderer Substanzen ähnliche Wirkungen hervorbringen. So färben namentlich aufser den Fetten noch sehr stark: Stearinsäure, Paraffin, Waohs, Wallrath, Berywachs (Ozokerit); etwas weniger stark: Colophonium, Mastix, Gutta percha, Caoutchouc; noch weniger, aber noch ganz intensiv: Bernstein, Zucker, Stärke, Baumioolle u. a. m. Die letzteren wirken jedoch nur färbend, wemn sie in den bis $300^{\circ}$ erbitzten Schwefel eingebracht und gut mit ihm durchgerührt werden.

Einige dieser Substanzen mögen noch geringe Mengen von Fett enthalten haben, von mehreren derselben wird man diefs zwar nicht bebaupten, allein man könnte glauben, dafs sie wit den fettigen Fingern berührt worden sind und dadurch färbend gewirkt haben. Um jedem Einwande der Art zu begegnen, habe ich einige Krystalle von weifsem Candiszucker in destillirtes Wasser gelegt, und nachdem die üufsere Schicht derselben aufgelöst war, durch Fliefspapier abgetrocknet, und olne sie mit den Fingern zu berühren in den heifsen Schwefel gebracht, der durch zweimalige Destillation gereinigt war. Auch diese färbten ihn.

Die Farbe, welche der Schwefel durch Zucker, Stärke, Baumwolle u. dergl. m. annimmt, ist zwar mebr braun als

1) Journal für praktische Chemie Bd. LXVII, S. 369.

Poggendorf's Annal. Bd. XCIX. 
roth, aber die Lösung desselben in Schwefelkohlenstoff zeigt stets die reine rothe Farbe.

Es geht hieraus hervor, dafs auch andere als fette Substanzen den Schwefel färben, und es kann daher die rothe Farbe desselben nicht dazu dienen, die Gegenwart eines Fettes zu erkennen. Es scheint, dafs sehr verschiedene Substanzen sich in höherer Temperatur so zersetzen, dafs ein gewisser Bestandtheil derselben sicb mit dem Schwefel verbindet, und mit ihm jenen stark färbenden Körper bildet, von dem es mir indefs bis jetzt nicht gelungen ist, ihu vou überschüssigem Schwefel zu trennen.

Die färbende Eigenschaft desselben ist so grofs, dafs nicht nur der Schwefel, den man mit den Händen berührt hat, durch das Fett, welches dadurch an ihn abgegeben ist, sich roth färbt, wenn er über $300^{\circ} \mathrm{C}$. erhitzt wird, sondern dafs auch Schwefel, der mehrere Male bis $300^{\circ} \mathrm{C}$. erbitzt, und jedes Mal ausgegossen worden ist, auch wenn man ihn gar nicht mit den Händen berührt hat, doch eine röthliche Farbe annimmt, die wahrscheinlich von Staubtheilchen berrübrt, welche sich während des Erkaltens aus der Luft auf ihn absetzen, und bei dem neuen Erhitzen jene färbende Verbindung eingehen.

Durch diese Versuche bin ich auf einige die allotropischen Zustände des Schwefels betreffende Thatsachen geführt worden. Bei Feststellung derselben hatte ich mich der Unterstützung des Hrn. R. Weber, und zwar in solchem Maafse zu erfreuen, dafs diese Arbeit als eine von uns gemeinschaftlich ausgeführte betracbtet werden kann.

Erhitzt man gewöbnlichen gelben Schwefel bis $3 \mathbf{3 0}^{\circ} \mathrm{C}$. oder bis zu der Temperatur, bei welcher derselbe, nachdem er dickflüssig geworden ist, wieder anfängt dünnlüssig zu werden, und läfst ihu dann langsam erkalten, so ist er, wie bekannt, vollständig oder fast vollständig in Schwefelkohlenstoff löslich. Damit er diefs sey, ist es übrigens gut, ihn während der Abkühlung wiederholt zu schütteln, weil sonst der an der Wand des Gefärses be- 
findliche zu schnell erkaltet, und dadurch in Schwefelkohlenstoff unlöslich wird.

Läfst man nämlich Schwefel, der bis $300^{\circ}$ C. erhitzt worden ist, schnell erkalten, so löst er sich nicht mehr vollständig in Schwefelkoblenstoff, sondern hinterlärst, je nachdem die Abkühlung mehr oder weniger schnell erfolgt ist, einen gröfsern oder geringern Antheil ungelöst. Nimmt man die Abkühlung auf die Weise vor, dafs man den Schwefel als einen dünnen Strabl in kaltes $W_{\text {asser giefst, }}$ so dafs man den bekannten weichen Schwefel erbält, so hinterläfst dieser, wie aus der folgenden Tabelle hervorgeht, einige und dreifsig bis einige und vierzig Proc. seines Gewichtes ').

Der lösliche Antheil des weichen Schwefels enthält aber noch zwei verschiedene Modificationen des Schwefels. Destillirt man vämlich einen Theil des Schwefelkoblenstoffs von dieser Lösung ab, und läßst dann die Flüssigkeit erkalten, so krystallisirt octaëdrischer Schwefel heraus. Nimmt man diesen aus der Flüssigkeit, und destillirt eine neue Quantität des Schwefelkoblenstoffs ab, so dafs man beim Erkalten eine neue Menge octaëdrischen Schwefels erbält, so bleibt bei Wiederbolung dieser Operation schliefslich eine zähe Masse zurück, die sich zu Fäden ziehen läfst. Dieselbe enthält noch Schwefel. Ueberlăfst man sie sich selbst, so verdunstet der Schwefelkohleustoff und dann scheidet sich der Schwefel als eine krümliche Masse aus. Dieser Schwefel war offenbar noch leichter in Schwefelkohlenstoff löslich als der octaëdrische Schwefel, denn er hat sich erst nach diesem ausgeschieden, allein dennoch löst er sich, sobald er von dem Schwefelkohlenstoff getreunt worden, nicht wieder in demselben auf. Sollte die krümliche Masse, was bisweilen vorkomint, noch kleine

1) Hr. Ch. Sainte-Claire Deville giebt in seiner Abhandluog: Des modifications du soufre sous l'influence de la chaleur et des dissolvants (Ann. de Chim. 3. Ser. XLVII, 99) an, dals er 35 Proc. darin gefunden labe. 
Krystalle einschliefsen, so lösen diese sich auf, der krünlich abgeschiedene Schwefel aber ist unlöslich, selbst in kochendem Schwefelkohlenstoff.

Ist der weiche Schwefel, aus welchem die krümliche Masse dargestellt wird, nur ein Mal bis $300^{\circ} \mathrm{C}$. erhitzt und ist jede Beriihrung mit den Fingern vermieden worden, so ist die krümliche Masse rein gelb. War hingegen der weiche Schwefel mehrmals geschmolzen und ausgegossen, so erscheint sie bald mebr bald weniger roth gefärbt. Deshalb ist sie früher als rotber Schwefel von mir bezeichnet worden. Da sie in Schwefelkohlenstoff löslich ist, ein Mal aber von diesem Auflösungsmittel getrennt sich nicht wieder in demselben auflöst, so unterscheidet sie sich sowohl von dem löslichen, als von dem unlöslichen Schwefel und ist als eine besondere allotropische Modification anzusehen. Sic verhält sich in dieser Beziehung ganz wic die Kieselsäure, worauf ich auch bereits bei dem rothen Schwefel aufmerksam gemacht habe ${ }^{1}$ ). Mit Ausnahme der Farbe, die, wie erwähnt, schwanken kann, zeigt sie alle Eigenschaften welche von diesem angeführt worden sind. Wird sie geschmolzen und langsam abgekühlt, so verwandelt sie sich in gewöhnlichen löslichen Schwefel.

Von der Gegenwart dieser Modification scheint das auffallende Verhalten des schnell gekühlten weichen Schwefels abzuhängen. Läfst man nämlich den weichen Schwefel so lange liegen, bis er vollständig erbärtet und brüchig ist, wozu bekanntlich mehrere Tage erforderlich sind, so enthält er viel weniger von dieser Modification als im frischen weichen Zustande, wie sich diefs bei Vergleichung der Columnen 3 und 7 der folgenden Tabelle ergiebt, in welcher die Versuche zusammengestellt sind.

1) Diesc Aunalen Bd. XCII, S. 308. 


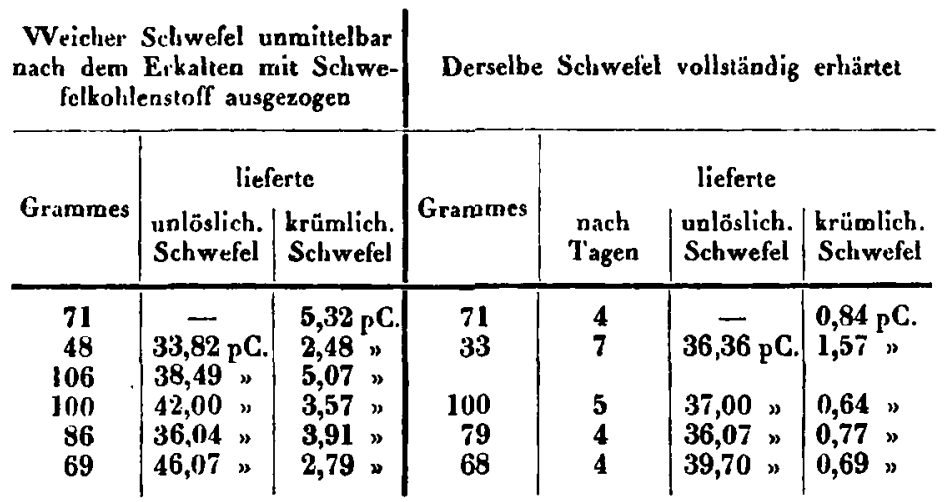

Ob bei der Umwandlung des weichen Schwefels in harten, der in ihın enthaltene krümliche sich in unlöslichen oder in löslichen Schwefel umwandele, wufs ich für jetzt unentschieden lassen. Zwar sollte man glauben, dafs sich diefs dadurch entscheiden lasse, dafs man die Menge des unlöslichen Schwefels der in dem weichen enthalten ist, vergleicht mit der in demselben Schwefel nach dem Erhärten vorhandenen Menge. Allein wie aus den vorstehenden Versuchen bervorgeht, lassen sich diese Bestimmungen nicht mit hinreichender Sicherheit ausfüluren, theils weil der uulösliche Schwefel wegen seiner porösen Beschaffenheit leicht etwas Schwefelkohlenstoff zurückbält, vorzugeweise aber weil man trotz aller angewandten Vorsicht nicht sicher ist, dafs der untersuchte erhärtete Schwefel genau bei derselben Temperatur ins Wasser gelangt, und genau unter denselben Umständen abgekühlt, also von derselben Beschaffenheit ist, wie der ihm entsprechende weiche.

Die Quantität des krümlichen Schwefels läfst sich zwar auch nicht vollkowmen sicher bestimmen, aber doch annähernd genug um erkennen zu lassen, dafs die Menge desselben in dem weichen Schwefel beträchtlich gröfser als in dem erhärteten ist. Deshalb glaube ich annehmen zu dürfen, dafs die Biegsamkeit und Elasticităt des weichen Schwefels auf der Anwesenheit dieser Modification beruht.

Diese Annahme wird dadurch noch wahrscheiulicher, 
dafs auch sebr kleine Mengen anderer Beimischungen das Verhalten des Schwefels in ähnlicher Weise ändern. Ist nämlich der Scluwefel durch eine der oben erwälnnten Substanzen intensiv roth oder schwarz gefärbt, wozu nur 0,0003 seines Gewichts ron Paraffin erforderlich ist, und man kühlt ihn, nachdem er bis $300^{\circ} \mathrm{C}$. erhitzt worden, plötzlich $a b$, indem mau ihn in baltes Wasser oder auf eine kalte Platte giefst, so bleibt er während längerer Zeit so weich und scbmierig, dafs man die einzelnen Stücke zusammenkneten und zu einem Stück vereinigen kann. Dabei lälst er sich in lange dünne Fäden ziehen, und behält diese klcbrige Beschaffenheit mehrere Stunden, oft während eines Tages. Ein Verhalten, das ich schon früher von dem schwarzen Schwefel beschrieben habe.

Aber nicht nur die Art des Erstarrens wird durch diese geringe Beimischung verändert, sondern auch im flüssigen Zustande verbält sich dieser Schwefel anders als der gewöhnliche, denn er wird zwar in höherer Temperatur dickfüssig, allein viel weniger als der gewöhnliche Schwefel.

Da die weiche und schmierige Beschaffenbeit des schwarzen Schwefels von der Beimischung einer so geringen Menge einer fremden Substanz herrührt, so ist es auch wabrscheinlich, dafs die Biegsamkeit und Elasticität des gelben, sogenannten weichen Schwefels durch die geringe Menge des krümlichen Schwefels entsteht, welche er enthält.

Solche Veränderungen der Eigenschaften durch die Gegenwart von geringen Mengen fremder Substanzen sind gewifs nicht bäufig; doch fehlt es nicht an einem Beispiel, und es braucht in dieser Beziehung nur an die Umwandlung des Eisens in Stahl erinnert zu werden.

Die verschiedenen allotropischen Zustände des Schwefels sind hiernach folgende:

1. Prismatischer Schwefel.

2. Octaëdrischer Schwefel.

Beide in Schwefelkoblenstoff löslich.

3. Unlöslicher Schwefel.

4. Krümlicher Schwefel, der in seinem frischen $\mathrm{Zu}$ - 
stande in Schwefelkohleustoff löslich ist, ein Mal ausgeschieden sich aber nicht wieder darin auflöst.

Dieser ist früher als löslicher und unlöslicher rother Schwefel von mir beschrieben worden. Wenn nämlich der weiche Schwefel auch nur die geringste Menge färbender Substanz enthält, so bleibt diese stets bei dem krümlichen Schwefel, weil sie, wie dieser, leichter als der gewöhnliche Schwefel in Schwefelkohlenstoff löslich ist, und daher sowohl in der Mutterlauge mit ihm zurückbleibt, als auch bei gänzlicher Entziehung des Schwefelkohlenstoffs ihm in fester Form anhaftet.

5. Der schwarze Schwefel, der, da er durch Beimischung fremder Substanzen entsteht, zwar nicht als ein allotropischer Zustand, wohl aber als eine besondere Modification des Schwefels zu betrachten ist, weil er sich nicht durch die Farbe allein, sonderv auch durch die oben erwähnten Eigenschaften von den verschiedenen Zuständen des Schwefels unterscheidet.

\section{Ueber die Bestimmung der specifischen} Gexichte; von Dr. Gustav Jenzsch.

Seit 1854 bediente ich mich stets mit Vortheil einer Methode zur Bestimmung der specifischen Gewichte, welche ich hier in der Kürze mittheile.

Man füllt ein kleines, mit gut eingeriebenem hoblen Glasstöpsel versehenes Flacon (wie solche Hr. Professor Danger in Paris anfertigen lälst) mit destillirtem Wasser, bringt es in ein metallenes (silbernes) becherförmiges Gefäfs und kocht dasselbe darin unter destillirtem Wasser so lange, bis sich keine Luftblasen mehr entwickeln. Man küblt das Ganze bis zu einer beliebigen Temperatur ab, welche 